\title{
Structural and Functional Evolution of the Vasopressin/Oxytocin Superfamily: Vasopressin-Related Conopressin Is the Only Member Present in Lymnaea, and Is Involved in the Control of Sexual Behavior
}

\author{
R. E. Van Kesteren, ${ }^{1}$ A. B. Smit, ${ }^{1}$ R. P. J. De Lange, ${ }^{1}$ K. S. Kits, ${ }^{1}$ F. A. Van Golen, ${ }^{1}$ R. C. Van Der Schors, ${ }^{1}$ N. \\ D. De With, ${ }^{1}$ J. F. Burke, ${ }^{2}$ and W. P. M. Geraerts ${ }^{1}$ \\ ${ }^{1}$ Graduate School Neurosciences Amsterdam, Institute of Neurosciences, Faculty of Biology, Department of \\ Experimental Zoology, Vrije Universiteit, Amsterdam, The Netherlands and ${ }^{2}$ Sussex Centre for Neuroscience, \\ School of Biological Sciences, University of Sussex, Brighton, United Kingdom
}

It has been suggested that the gene duplication that led to the formation of the vasopressin/oxytocin two-gene family occurred early during vertebrate evolution. However, the existence of both vasopressin- and oxytocin-related peptides in invertebrates suggests that this duplication may have occurred much earlier, although there is no evidence for the co-occurrence of vasopressin- and oxytocin-related peptides in the same invertebrate species. We report here that in Lymnaea only the vasopressin-related peptide Lysconopressin, but not an oxytocin-related peptide, is present. Moreover, it is very likely that an oxytocin-like cDNA or gene is absent. The conopressin gene is expressed in neurons that control male sexual behavior, and its gene products are present in the penis nerve and the vas deferens. Conopressin induces muscular contractions of the vas deferens and inhibits central neurons that control female reproductive behavior. Thus, although structurally related to vasopressin, conopressin has functional and behavioral characteristics typical for oxytocin. Physiological and receptor binding data suggest that conopressin and $\left[l l e^{8}\right]$-conopressin, a synthetic oxytocin-like analog of conopressin, are functionally equivalent in Lymnaea, and that the chemical nature of the amino acid residue at position 8 does not result in a functional difference. Therefore, we suggest that invertebrates contain only a single member of the vasopressin/oxytocin gene family and that the amino acid change that distinguishes vasopressin from oxytocin is functionally neutral in invertebrates.

[Key words: conopressin, vasopressin/oxytocin gene family, evolution, male sexual behavior, peptide sequencing, gene cloning, receptor interaction, Lymnaea stagnalis]

\footnotetext{
Received Oct. 3, 1994; revised Apr. 20, 1995; accepted Apr. 24, 1995

This work was supported by the Foundation for Life Sciences (SLW; Grant 805-26-203), which is subsidized by the Netherlands Organization for Scientific Research (NWO). Support was also received from the EC (BIO2CTCT930169). We thank Dr. P. Van Veelen for the mass determination, Dr. G. Reich for performing the anti-oxytocin RIA. Mrs. E. R. Van Kesteren and Mr. J. C. Lodder for technical assistance, and Mrs. T. Laan for secretarial assistance.

Correspondence should be addressed to Dr. R. E. Van Kesteren, Department of Zoology, Faculty of Biology, Vrije Universiteit, De Boelelaan 1087, 1081 HV Amsterdam.

Copyright $\bigcirc 1995$ Society for Neuroscience $0270-6474 / 95 / 155989-10 \$ 05.00 / 0$
}

Vasopressin and oxytocin are nonapeptides that are present in all placental mammals. Although similar in structure, they serve different functions (Ramsay, 1983). Vasopressin has anti-diuretic activities and is involved in hydromineral regulation, whereas oxytocin has uterotonic and milk-ejection activities and regulates aspects of reproductive behavior. Peptides related to both vasopressin and oxytocin are present in all vertebrate classes, except the cyclostomes, which have only the vasopressin-related peptide vasotocin (reviewed by Acher, 1993). Peptides of the vasopressin family have a basic amino acid residue at position 8 in common, whereas oxytocin and related peptides have a neutral amino acid residue at this position. The chemical nature of this amino acid residue is thought to be of critical importance in the interactions of the peptides with their respective receptors.

The structure of the protein precursors of the vasopressin/ oxytocin superfamily are very similar, with a signal peptide domain followed by the nonapeptide, neurophysin, and copeptin domains (reviewed by Acher, 1993), although the copeptin domain is lacking in the oxytocin and mesotocin precursors. The precursor proteins are encoded by different genes that have an identical exon-intron organization in mammals (Schmale et al., 1983; Ivell and Richter, 1984; Ruppert et al., 1984; Sausville et al., 1985; Hara et al., 1990), bony fish (Morley et al., 1990), and cyclostomes (Heierhorst et al., 1992). Together with the phylogenetic distribution of the peptides, these data suggest that the superfamily evolved from an ancestral gene by the mechanism of gene duplication. Because lampreys and hagfish have only vasotocin (Lane et al., 1988; Heierhorst et al., 1992), it has been hypothesized that the vasotocin gene is the present-day representative of the ancestral gene, and that the gene duplication occurred between the radiation of cyclostomes and cartilaginous fish, aboul 450 million years ago (Acher, 1980).

Vasopressin-related peptides are not restricted to the vertebrates, but have been identified in several invertebrate phyla as well, including insects (Proux et al., 1987), molluscs (Cruz et al., 1987; McMaster et al., 1992) and annelids (Salzet et al., 1993). Oxytocin-related peptides have similarly been found in molluses (Reich, 1992) and annelids (Oumi et al., 1994). The presence of both vasopressin- and oxytocin-related peptides in invertebrates leads to an alternative hypothesis stating that duplication of the ancestral gene occurred prior to the divergence of vertebrates and invertebrates, over 600 million years ago (Van 
Kesteren et al., 1992). However, this hypothesis has not been verified by experimental data showing co-occurrence of vasopressin- and oxytocin-related peptides in a single invertebrate species, or by demonstrating functional divergence of the two types of peptide in invertebrates. Thus, species variation instead of gene duplication may explain the appearance of either vasopressin- or oxytocin-related peptides in invertebrates.

In this article, we attempt to distinguish between these possibilities by studying vasopressin- and oxytocin-related peptides in the mollusc Lymnaea stagnalis. Previous cDNA cloning studies (Van Kesteren et al., 1992) have identified a vasopressin-like precursor, pro-Lys-conopressin, in Lymnaea. To demonstrate that conopressin has the typical tertiary structure of vasopressin-related peptides and is transported to peripheral target tissues, we have now identificd Lys-conoprcssin from both the CNS and the male copulatory organs. At the same time, we show evidence for the absence of an oxytocin-related peptide or cDNA. Moreover, genomic analysis strongly suggests that the conopressin gene is a single copy gene in Lymnaea, and that related genes are absent. Although structurally related to vasopressin, conopressin has functions in the control of sexual behavior that in mammals usually are associated with oxytocin. The implications of these findings for theories of the molecular and functional evolution of the vasopressin/oxytocin superfamily are discussed.

\section{Materials and Methods}

Animals, peptides, and antibodies. Adult specimens of $L$. stagnalis (shell height $28-34 \mathrm{~mm}$ ), bred in the laboratory under standard conditions, were used. Synthetic Lys-conopressin G was obtained from Bachem Feinchemikalien AG (Budendorf, Switzerland). [1le ${ }^{8}$-conopressin (Cys-Phe-Ile-Arg-Asn-Cys-Pro-Ile-Gly-amide) was synthesized using a peptide synthesizer from Applied Biosystems (Foster City, CA). After formation of the intramolecular disulphide bridge, the final structure and purity of the peptide was confirmed by mass spectrometry and amino acid sequencing. Antiserum W1E was a gift of Dr. J. P. H. Burbach (Rudolf Magnus Institute, Utrecht, The Netherlands) and recognizes the carboxy-terminal sequence of Arg-vasopressin (Liu and Burbach, 1987), and antiserum 121 was a gift of Dr. H. W. Van Leeuwen (Netherlands Institute for Brain Research, Amsterdam, The Netherlands) and recognizes the carboxy-terminal sequence of Lys-vasopressin (Swaab and Pool, 1975). An anti-CDCH antiserum was used as described (Van Minnen et al., 1989). A synthetic peptide fragment corresponding to the 11 amino-terminal amino acids (SLDTGMVTSRE) of Iymnaea neurophysin was a gift of Dr. R. H. M. Ebberink (Applied Biosystems, Maarssen, The Netherlands). An antiserum to the fragment was raised in mice as described (Van Minnen and Schallig, 1990).

Purification of conopressin. Relevant tissues (CNS, or vas deferens and penis complex together) of 1000 snails were homogenized in 0.1 $M$ acetic acid and centrifuged. The supernatant was applied to Supelclean C-8 cartridges (Supelco Inc., Bellefonte, USA) previously activated with methanol and solvent $\mathrm{A}(7.5 \mathrm{~mm}$ trifluoroacetic acid). After loading, cartridges were washed with $4 \mathrm{ml}$ solvent $\mathrm{A}$, and peptides were eluted with $2 \mathrm{ml}$ solvent B $(7.0 \mathrm{~mm}$ trifluoroacetic acid in $60 \%$ acetonitrile). The effluents were lyophilized and redissolved in bidistilled water. High-performance gel permeation chromatography (HPGPC) and reverse-phase high-performance liquid chromatography (rpHPLC) were performed using an M-720 system controller, an M-730 data module, an M-600 solvent delivery system, and an M-441 UV/VB absorbance detector (Waters Assoc., Bedford, MA). The flow rate was $1 \mathrm{ml} / \mathrm{min}$, and fractions of $1 \mathrm{ml}$ were collected.

The peptide extract was applied to tandemly arranged Protein-Pak I-125 and I-300 gel permeation columns (Waters Assoc.) in several successive runs. The ruming solvent consisted of $30 \%$ acetonitrile in $7.5 \mathrm{~mm}$ TFA. Fractions containing the small peptides were pooled, lyophilized, redissolved in bidistilled water, and applied to a Nucleosil $300 \mathrm{C}-18$ column $(5 \mu \mathrm{m}, 4.6 \times 250 \mathrm{~mm})$, equilibrated with solvent $\mathrm{A}$, in several successive runs. Elution was achieved by a linear gradient of $0-10 \%$ solvent B in $5 \mathrm{~min}, 10-35 \%$ solvent $\mathrm{B}$ in $35 \mathrm{~min}$, and $35-100 \%$ solvent B in 25 min. Fractions were lyophilized, redissolved in bidistilled water, and tested in a dotting immunoassay (DIA) according to
Li et al. (1989). In short, $1 \%$ of each fraction was dot blotted on nitrocellulose paper, heat fixed at $106^{\circ} \mathrm{C}$ for $15 \mathrm{~min}$, and then stained with antisera $\mathrm{W} 1 \mathrm{E}$ and 121. Corresponding immunoreactive fractions were pooled and applied to a Nucleosil 120 C- 18 column $(3$ p.m, $4.6 \times 150$ $\mathrm{mm}$ ) equilibrated with solvent $A$. Elution was achieved by a linear gradient of $20-35 \%$ solvent B in $60 \mathrm{~min}$. Fractions were lyophilized, redissolved in bidistilled water, and screened in the DI $\Lambda$. The immunoreactive fraction was applied to the same $\mathrm{C}-18$ column equilibrated with $25 \mathrm{mM} \mathrm{NH}_{4} \mathrm{Ac}$ for the CNS material. Elution was achieved by a linear gradient of $10-40 \%$ of $25 \mathrm{~mm} \mathrm{NH}_{4} \mathrm{Ac}$ in $60 \%$ acetonitrile in 60 min. The vas deferens and penis complex material was applied to the same column equilibrated with $0.05 \% \mathrm{HCl}$, and elution was achieved by applying $0.05 \% \mathrm{HCl} / 60 \%$ acetonitrile in a linear gradient of $0-5 \%$ in $5 \mathrm{~min}$, and $5-35 \%$ in $60 \mathrm{~min}$. Fractions were lyophilized, redissolved in bidistilled water, and screened using the DIA.

Sequencing, co-elution, and mass determination. The immunoreactive fraction of the final HPLC step was subjected to automated Edman degradation using a model $473 \mathrm{~A}$ pulse liquid protein sequencer ( $\mathrm{Ap}$ plied Biosystems). To verify the sequence and complete the structural characterization, synthetic Lys-conopressin was used in co-elution experiments employing the same HPLC system, solvents, and gradients as in the first and the third rpHPLC step described above. In addition, the purification procedure was repeated as described above, and the immunoreactive fraction of the final HPLC step was subjected to mass spectrometry using a Bio-ion 20/30 plasma desorption mass spectrometer (Applied Biosystems).

Anti-oxytocin radioimmunoassay. CNS of 200 snails were homogenized, prepurified, and subjected to HPGPC as described above. All fractions were lyophilized, redissolved in bidistilled water, and tested in an anti-oxytocin radioimmunoassay as described (Reich, 1992).

Polymerase chain reaction (PCR) amplification of putative oxytocin encoding $c D N A s$. Two degenerate oligonucleotides, OT1 and OT2, were synthesized, based on the putative oxytocin-like sequences Cys-(Phe/ Tyr)-(Phe//le)-Arg-Asn-Cys-Pro-(Leu/lle/Val)-Gly and the following amidation and processing sequence Gly-Lys-Arg [O11: 5'-GGAAGCTTG(TC)T(AT)(TC)(AT)T(ATC)(AC)G(GATC)AA(TC)TG(TC)CC(GATC)(ATC)T-3'; OT2: 5'-GGAAGCTTG(TC)CC(GATC)(ATC)T(GATC)GG(GATC)GG(GATC)AA(GA)(AC)G-3']. Both oligonucleotides were provided with Hind III restriction site extensions on the $5^{\prime}$ ends and used as primers in a PCR as described (Van Kesteren et al., 1992). In short, cDNA was isolated from a $\lambda g t 10 \mathrm{cDNA}$ library of the CNS (Vreugdenhil et al., 1988) and used as a template. As reverse primer, a $\lambda$ primer was used, which is complementary to a sequence in the left arm of $\lambda \mathrm{gt} 10$ ( $\lambda$ primer: 5'-AGCAAGTTCAGCCTGGTTAAGTCC-3'). In the first PCR, cDNA was amplified between OT1 and the $\lambda$ primer, using 40 cycles: $94^{\circ} \mathrm{C}$ for $1 \mathrm{~min}, 52^{\circ} \mathrm{C}$ for $1 \mathrm{~min}$, and $72^{\circ} \mathrm{C}$ for $2 \mathrm{~min}$. After amplification, $5 \mu \mathrm{l}$ of the PCR mixture were reamplified under the same conditions, now using OT2 and the $\lambda$ primer. Amplified cDNA was digested with Eco RI and Hind III, cloned into M13mp18 and sequenced using the dideoxy chain termination method (Sanger et al., 1977).

Low stringency screening of Lymnaea $c D N A$ and genomic libraries for conopressin-related sequences. From an amplified cDNA library of Lymnaca CNS in $\lambda$ gt 10 (for details, see Vreugdenhil et al., 1988), as well as from an amplified Lymnaea genomic library in EMBL3 (for details, see Bogerd et al., 1993), recombinant phages $\left(3.0 \times 10^{5}\right.$ and $1.2 \times 10^{5}$, respectively) were plated on $245 \times 245 \mathrm{~mm}$ dishes $(0.6 \times$ $10^{5}$ phages/dish) and absorbed to replica Hybond $\mathrm{N}^{+}$filters (Amersham Int., Amersham, UK). After prehybridization for $16 \mathrm{hr}$, the filters were hybridized at $55^{\circ} \mathrm{C}$ for $60 \mathrm{hr}$ to a ${ }^{32} \mathrm{P}$-labeled probe that was generated by primer extension on a single stranded M13 clone containing the full length conopressin cDNA. The hybridization solution contained $6 \times$ $\mathrm{SSC}(1 \times \mathrm{SSC}=150 \mathrm{~mm} \mathrm{NaCl}, 15 \mathrm{~mm}$ sodium citrate; $\mathrm{pH} 7.4), 5 \times$ Denhardt's (according to Maniatis et al., 1982), 0.1\% SDS and $10 \mu \mathrm{g} /$ $\mathrm{ml}$ salmon sperm DNA. The specific activity of the probe was $>3 \times$ $10^{8} \mathrm{dpm} / \mu \mathrm{g}$. Filters were washed in $2 \times \mathrm{SSC} / 0.1 \% \mathrm{SDS}$ at $55^{\circ} \mathrm{C}$ for 30 $\mathrm{min}$ and autoradiographed. Positive clones were replated at lower plaque density and screened with the cDNA probe. Genomic clones were also screened with synthetic oligonucleotides specific for either the leader sequence or the neurophysin domain of the conopressin gene. Inserts from positive cDNA clones were subcloned and sequenced. Of three positive genomic clones, $\lambda$ DNA was mapped for restriction endonuclease sites for the enzymes Bgl II, Eco RI, Hind III, Pst I, Sal I, and $X b a$ I by partial digestion and hybridization to an oligonucleotide directed to the right arm of EMBL3. The clones were directly sequenced 
A

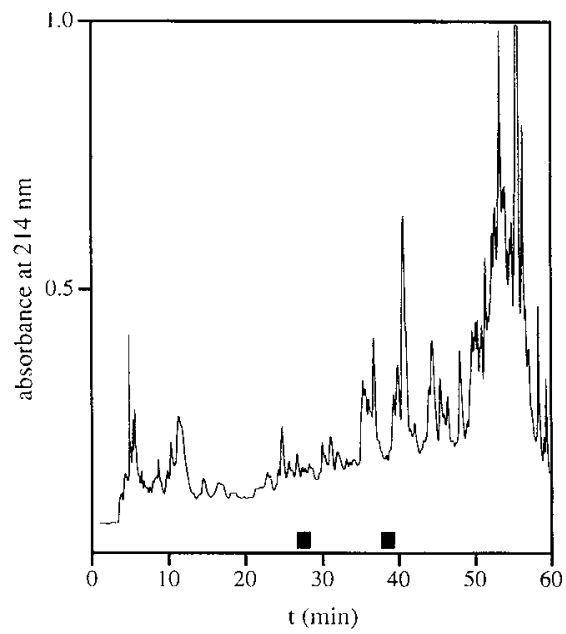

B



Figure 1. Purification of conopressin from the CNS of Lymnaea. A, Chromatogram of the first rpHPLC step, representing one-third of the total CNS material (330 animal equivalents). Synthetic Lys-conopressin co-eluted with fraction $39 . B$, Chromatogram of the final rpHPLC step, representing the total CNS material (1000 animal equivalents). Synthetic Lys-conopressin coeluted with fraction 48 , which was also used for molecular characterization. Immunoreactive fractions are indicated by black squares at the time axis. by linear amplification of the XDNA using $5^{\prime}$-end labeled conopressin specific primers and dideoxy chain termination mixtures (Lasham and Darlison, 1993).

Genomic Southern analysis. Genomic DNA was isolated from 100 CNS using the G-nome DNA Kit (Bio 101, La Jolla, CA), and digested with 200 units of either of the restriction enzymes Bgl II, Eco RI, Hind III, Pst I, and Xba I ( $8 \mu \mathrm{g}$ DNA/digestion). The digested DNA was electrophoresed on a $0.8 \%$ agarose gel and transblotted to Hybond $\mathrm{N}^{+}$ filter. After prehybridization, the filter was hybridized for $60 \mathrm{hr}$ to a ${ }^{32} \mathrm{P}-$ labeled PCR fragment containing the entire coding sequence of the conopressin cDNA (specific activity: $>5 \times 10^{\circ} \mathrm{dpm} / \mu \mathrm{g}$ ). Hybridization conditions were as described above. The filter was washed in $1 \times$ SSC at $55^{\circ} \mathrm{C}$ for $30 \mathrm{~min}$ and autoradiographed for $20 \mathrm{hr}$. Thereafter, the filter was washed in $0.2 \times \mathrm{SSC}$ at $65^{\circ} \mathrm{C}$ for $30 \mathrm{~min}$ and autoradiographed for $7 \mathrm{~d}$.

Immunocytochemistry and in situ hybridization. CNS and vas deferens were dissected and fixed in a mixture of $1 \%$ paraformaldehyde and $1 \%$ acetic acid or in Bouin's fixative. Tissues were dehydrated, embedded in paraffin, cut to $7 \mu \mathrm{m}$ sections, and alternately mounted on $0.5 \%$ gelatine $/ 0.5 \%$ chrome-alum coated microscope slides. For immunocytochemistry, dewaxed slides were incubated at $4^{\circ} \mathrm{C}$ for $16-18 \mathrm{hr}$ with primary antibodies diluted in Tris-buffered saline (TBS; $50 \mathrm{~mm}$ Tris, $150 \mathrm{~mm} \mathrm{NaCl} ; \mathrm{pH} 7.4$ ) containing $0.25 \%$ gelatine and $5 \%$ Triton X-100 (TBS-GT). Anti-neurophysin was diluted 1:200 and anti-Caudodorsal Cell Hormone (anti-CDCH) 1:500. After two 10 min rinses in TBS-GT, sections were incubated at $20^{\circ} \mathrm{C}$ for $1 \mathrm{hr}$ with a secondary antibody coupled to horseradish peroxidase, diluted $1: 100$ in TBS. After rinsing in TBS-GT, horseradish peroxidase was visualized by incubation in $0.05 \% 3,3$ diaminobenzidine tetrahydrochloride and $0.01 \% \mathrm{H}_{2} \mathrm{O}_{2}$ in TBS.

In situ hybridization procedures (pretreatment, labeling, hybridiza-

Table 1. Yield of PTH-amino acids in nine cycles of automated Edman degradation of purified Lys-conopressin

\begin{tabular}{llc}
$\begin{array}{l}\text { Edman } \\
\text { cycle }\end{array}$ & $\begin{array}{l}\text { PTH-amino } \\
\text { acid }\end{array}$ & $\begin{array}{l}\text { Yield } \\
\text { (pmol) }\end{array}$ \\
\hline 1 & Cys & $-"$ \\
2 & Phe & 26.80 \\
3 & Ile & 28.31 \\
4 & Arg & 2.06 \\
5 & Asn & 13.17 \\
6 & Cys & $-"$ \\
7 & Pro & 15.40 \\
8 & Lys & 12.47 \\
9 & Gly & 15.47
\end{tabular}

"PTH-cysteines are unstable during Edman degradation and, therefore, undetectable. tion) were carried out as described (De Lange et al., 1994). Hybridization was performed in the presence of $30 \%$ formamide, with a ${ }^{35} \mathrm{~S}$ labeled oligonuclentide complementary to the neurophysin encoding, part of the conopressin cDNA (5'-CGGTCCGACACACTGTCCGGTGCCACCTGGCCC-3') in a final concentration of $10 \mathrm{fmol} / \mu \mathrm{l}$.

Effects of Lys-conopre'ssin and [1/e ] conopressin on the vas deferens. The anterior part of the vas deferens was dissected, attached to a displacement transducer ( $\mathrm{Li}$ et al., 1992) in a $1 \mathrm{ml}$ chamber filled with snail Ringer (Geraerts et al., 1984). Peptides were added at different concentrations under continuous superfusion with Ringer at a flow rate of $1 \mathrm{ml} / \mathrm{min}$ and contractions were displayed on a recorder. Dose-response curves were constructed by plotting the contraction frequencies (mean of four experiments) semilogarithmically versus the concentration of the peptide.

Membrane potential effects of conopressin on caudodorsal cells. Electrophysiological recordings were performed on Caudodorsal cells (CDC) in situ in the isolated CNS (Kits et al., 1991 ). Membrane potential recordings were made using microelectrodes (Clark, Reading, UK) filled with $0.1 \mathrm{M} \mathrm{KCl}$ and with resistances of $15-30 \mathrm{M} \Omega$ connected to high input resistance amplifiers built in the laboratory. Recordings were plotted on paper with a Gould 2200 pen recorder. Bath saline had the following composition: $30 \mathrm{~mm} \mathrm{NaCl}, 10 \mathrm{mM} \mathrm{NaCH}_{3} \mathrm{SO}_{4}, 5 \mathrm{~mm} \mathrm{Na}$ $\mathrm{HCO}_{3}, 1.7 \mathrm{~mm} \mathrm{KCl}, 4 \mathrm{~mm} \mathrm{CaCl}, 1.5 \mathrm{~mm} \mathrm{MgCl}_{2}, 10$ mм Hepes; $\mathrm{pH}$ 7.8 .

\section{Results}

Purification and structural identification of Lymnaea conopressin

After the first rpHPLC step, two separate immunoreactive fractions (fractions 28 and 39; Fig. 1A) could be detected in CNS material with the antisera W1E and 121. Fraction 39 was further purified, and after a third rpHPLC step, two immunoreactive fractions (47 and 48; Fig. $1 B$ ) could be detected. The peptide material in fraction 48 was sequenced without modification of cysteine residues (Table 1). In the first and the sixth cycle of the Edman degradation, no PTH-amino acids could be detected. Assuming that the peptide contains cysteine residues at the corresponding positions, its amino acid sequence [(Cys)-Phe-Ile-ArgAsn-(Cys)-Pro-Lys-Gly] is identical to the primary sequence of Lys-conopressin (Cruz et al., 1987). Plasma desorption mass spectrometry indicated that the peptide has an $\mathrm{MH}^{+}$of 1036.7 Da. HPLC analysis demonstrated co-elution of synthetic Lysconopressin with the native peptide in two rpHPLC systems ( 7.5 mM TFA and $25 \mathrm{~mm} \mathrm{NH}_{4} \mathrm{Ac}$ ).

Further purification and characterization of the immunoreactive substance of fraction 28 (Fig. $1 A$ ) revealed a novel peptide with the amino acid sequence Leu-Ala-Ser-Leu-Gly-Gly-Lys- 
Ser-Ser-Ser-Arg-Pro-Ala-Pro-Arg-Gly-amide. The structure of this peptide was confirmed by mass spectrometry and co-elution with a synthetic form of the peptide. The carboxy-terminal sequence Pro-Arg-Gly- $\mathrm{NH}_{2}$ explains its immunoreactivity to the anti-vasopressin antisera. However, because it lacks the structural characteristics of the vasopressin/oxytocin superfamily (e.g., the presence of cysteine residues that can form a disulphide bridge), it is not further considered here.

Lys-conopressin could also be purified from the vas deferens and the penis complex together (data not shown). Its identity was established by amino acid sequencing and co-elution with synthetic Lys-conopressin.

\section{Anti-oxytocin radioimmunoassay}

A peptide extract of 200 Lymnaea CNS was size fractionated on HPGPC and all fractions were tested in a radioimmunoassay with ${ }^{125}$ I-oxytocin as the tracer (Reich, 1992). No immunoreactivity significantly above background could be detected in these fractions (data not shown).

\section{PCR amplification of putative oxytocin encoding cDNAs}

Amplification of $\lambda \mathrm{gt} 10 \mathrm{cDNA}$ using primer OT1 in combination with the $\lambda$ primer yielded many DNA fragments when analized by electrophoresis on an agarose gel. Reamplification of the PCR mixture using primer OT2 in combination with the $\lambda$ primer yielded a single DNA fragment of 700 base pairs (data not shown). This fragment was cloned, and 30 clones were sequenced and shown to contain the conopressin cDNA. To exclude the possibility that the amplification product consisted of the conopressin cDNA and a less abundant fragment representing a related cDNA species, -300 additional clones were hybridized to an oligonucleotide specific for the $3^{\prime}$ trailer sequence of the conopressin cDNA. No clones were found that did not hybridize, demonstrating that the amplification product most likely consisted of only the conopressin cDNA.

Low-stringency screening of Lymnaea cDNA and genomic libraries for conopressin-related sequences

Low-stringency hybridization of a cDNA library of Lymnaea CNS yielded 26 positive clones. After subcloning and sequence analysis, two of these appeared to contain the conopressin cDNA sequence. All others contained sequences that were not related to conopressin, and were apparently isolated because of short stretches of DNA showing slight homology with the conopressin cDNA sequence (data not shown).

Low-stringency hybridization (i.e., washing conditions: $2 \times$ SSC $/ 0.1 \%$ SDS at $55^{\circ} \mathrm{C}$ ) of a Lymnaea genomic library yielded 17 clones that after two rounds of screening still hybridized to the conopressin cDNA prohe. Of these clones, 10 hybridized to an oligonucleotide specific for the leader sequence of the conopressin cDNA, and 7 to an oligonucleotide specific for the neurophysin domain. There was no overlap in these two groups of clones. One clone ( $\lambda$ CP56) of the first group and two $(\lambda \mathrm{CP} 21$ and $\lambda C P 31$ ) of the second were used for restriction enzyme mapping and sequence analysis. The restriction map of $\lambda$ CP56 shows no overlap with those of $\lambda C P 21$ and $\lambda C P 31$, while the latter two have a large part in common. Within the overlapping part, however, $\lambda$ CP2 1 contains two $X b a$ I sites that are absent in $\lambda$ CP31, whereas $\lambda$ CP3 1 contains two Xba I sites and one $P s t$ I site that are absent in $\lambda \mathrm{CP} 21$ (Fig. $2 A$ ). Sequencing of the three clones revealed that the conopressin gene is composed of three exons interrupted by two introns at exactly the same locations as in the vasopressin and oxytocin genes of vertebrates (Fig. 2B). Exon $I$ and the $5^{\prime}$ part of intron 1 are located on $\lambda$ CP56 and the $3^{\prime}$ part of intron 1 and the rest of the gene are located on both $\lambda$ CP2 1 and $\lambda$ CP31 (Fig. 2). The exon sequences of $\lambda$ CP56 and $\lambda C P 21$ are identical to the conopressin cDNA sequence (Van Kesteren et al., 1992). Clone $\lambda$ CP31, however, has two conservative third-base substitutions in the neurophysin encoding part of the gene (one in exon II and one in exon III) and numerous substitutions in the $3^{\prime}$ noncoding sequence and in the introns, as well as an 18 base pair insertion in intron 2 (Fig. $2 B$ ).

In exon III, at 14 nucleotides after the first putative polyadenylation signal (at nucleotide 1245 of the $2.5 \mathrm{~kb}$ cDNA; Van Kesteren et al., 1992), sequence identity between gene and cDNA ends. Since many additional cDNA clones have been sequenced, all containing poly(A)-tails at position 1245 (data not shown), we suggest that the rest of the cDNA is not a part of the conopressin gene and became unspecifically ligated to the conopressin cDNA during construction of the library.

\section{Genomic Southern analysis}

Southern blots containing genomic DNA digested with five different restriction enzymes did not show different hybridization patterns when hybridized to a PCR fragment of the coding region of the conopressin cDNA at Jow $\left(1 \times \mathrm{SSC}, 55^{\circ} \mathrm{C}\right)$ or at high $\left(0.2 \times \mathrm{SSC}, 65^{\circ} \mathrm{C}\right)$ stringency (Fig. 3). In each lane, three to six bands hybridized at low stringency and could not be washed off at high stringency. Only in the lanes containing $B g l$ II and Pst I digested DNA, a few faint bands were present that disappeared after high-stringency washing.

\section{Localization of conopressin and conopressin transcripts}

To determine the site of synthesis of conopressin, anti-neurophysin antiserum and conopressin-specific oligonucleotides were applied to alternate sections of the CNS. Both the antiserum and the oligonucleotide probe recognized one neuron at the caudal surface of each pedal ganglion (not shown) and neurons of the anterior lobes of both cerebral ganglia (Fig. $4 A, B$ ). The antineurophysin antiserum stained also axon bundles in the penis nerve (Fig. 4C) and along the vas deferens (Fig. 4D). Positive staining was also observed in axons in the cerebral ganglia located in close proximity of the CDC (Fig. $4 E$ ). When the alternate sections were stained with anti-CDCH, to visualize the axons of the $\mathrm{CDC}$, anti-neurophysin positive axons and anti-CDCH positive axons could bc observed within the cerebral ganglia in close proximity of each other (Fig. $4 E, F$ ).

\section{Effects of Lys-conopressin and [Ile $\left.e^{*}\right]$-conopressin on the vas deferens}

Application of Lys-conopressin or $\left[\mathrm{Ile}^{8}\right]$-conopressin to the dissected anterior vas deferens (the part of the vas deferens that runs from the body wall to the penis; Barraud, 1957) elicited contractions that increased with frequency in a dose-dependent manner. The contraction frequency during the first minute following application (mean of four experiments) was used to construct dose-response curves (Fig. $5 A$ ). The calculated $\mathrm{EC}_{50}$ values were $4 \pm 1.2 \mathrm{nM}$ for Lys-conopressin and $1 \pm 0.5 \mathrm{nM}$ for $\left[\mathrm{Ile}^{8}\right]$-conopressin (mean $\pm \mathrm{SD}$ ). Desensitization of the conopressin receptor by repeated applications of Lys-conopressin resulted in decreased responses to both Lys-conopressin and [Ile ${ }^{8}$-conopressin, whereas the response to an unrelated -FFamide peptide ( $\mathrm{Li}$ et al., 1995) did not desensitize (Fig. 5B), 
A
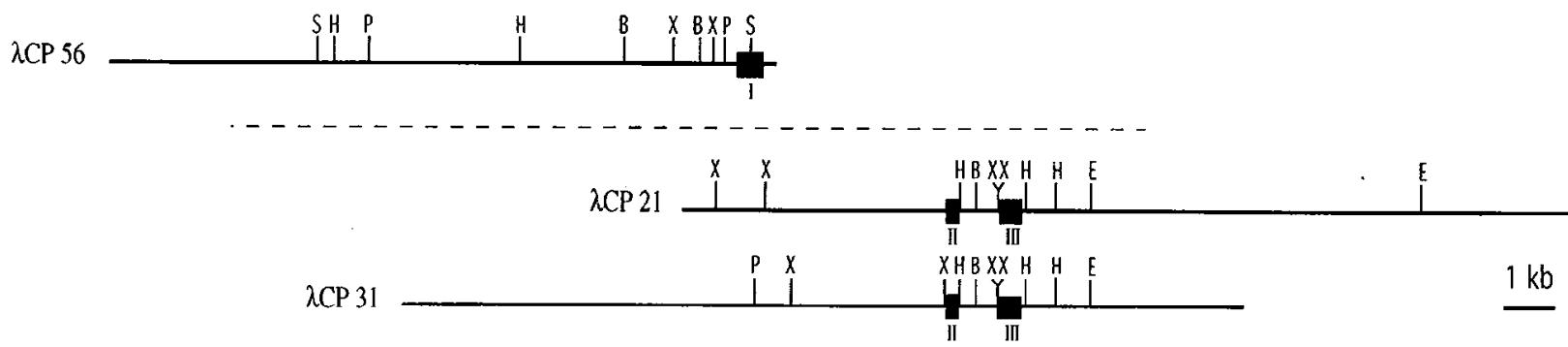

$\mathrm{B}$

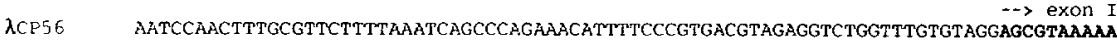
גСР56 CGCGACAAACAAAGACATTTATAAAGTAGAGATAGCATCAGGAAGAGCAGTCATTTTCTGACTAAGACATTTACTCCGAAATTCAAGTCGAAATTTCTCACCTTAGTTTATTAAATATTTGAATTTTTT ALP56 TTTCAAAATTATAAACTTTCTAACAACTTTGATTGTTTTAATTTTGATAGAGTAGATATTTTTTTAAAAAAATAGATTATTTTTTGACGTAAGAGATACGTTCCGAAATTAATTGATTTCCCTTCCCATGATGCC גCP56 ACGCGGCTTGTGAGGACTATATCAGAGTCGTTCAGGATCTATTCCGACTCCACGAGATCGGACCAGACGTCTGCGGCAACGGATTCAACAAGAGATTCGTCGACTGTTTGCATAGCCGCGACCCTAGGGTGCAGT

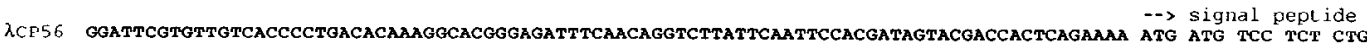
ATG ATG TCC TCP CTG TGT GGT ATG CCA CTG ACC TAT Het Met Ser Ser Leu Cys Gly Met Pro Leu Thr Tyr

2C856 CTG CTG ACC GCC GCT GTC CTG TCA CTG TCA CTG ACG GAC GCT TGT TTC ATC AGg AAC TGT CCA AAA GGT GGA AAG CGA TCG TRA GAC ACG GGC ATG GTG ACG

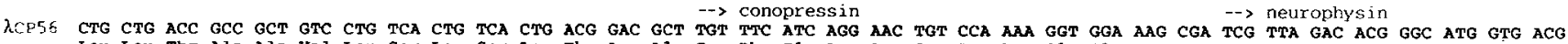

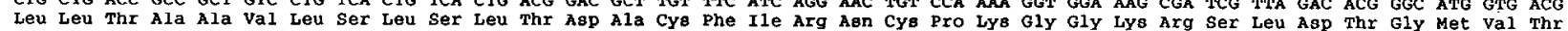

ACP56 TCA CGT GAG GTAATTATCCTAATTATACATTTCATCCCGTGGCCTGGTCCATAAGGTCCACAGCCCTCAATTAAATCAACTAT. Ser Arg Glu

$\lambda$ CP2 $1 \quad \ldots \ldots \ldots \ldots \ldots$ GTGTTGATGTCTTGAGAAATATGTGGATGTGTTGATGTCTTGAGAAATGTGTGGTGCTTTTGATGTCTTGAGAAATGCGTGTATGTGCTAATGGTGTCTCCCTCCTCTCTCCTCTGGTCAG $\lambda \subset \mathrm{P} 31 \quad \ldots \ldots \ldots \ldots \ldots$. $-\rightarrow$ exon II

ACP21 TGC ATG AAG TGT GGG CCA GGT GGC ACC GGA CAG TGT GTC GGA CCG AGC ATC TGC TGT GGT CAG GAC TTT GGC TGT CAT GTC GGG ACA GCG GAG GCG GCG GTA ACP 32 Cys Met Lys Cys Gly Pro Gly Gly Thr Gly Gln Cys Val Gly pro Ser Ile Cys Cys Gly Gln Asp phe Gly Cys His val Gly Thr Ala Glu Ala Ala val $\lambda C P 21$ TGC CAA CAG GAG AAC GAC AGC TCG ACC CCG TGC CTS GTC AAG GAS GAG GCG TGT GGG TCA AGG GAT GCG GGC AAC TGT GTG GCA GAC GGC ATA TGC TGT GAT ACP3 Cys Gin Gln Glu Asn Asp Ser Ser Thr Pro Cys Leu val Lys Gly Glu Ala Cys Gly ser Arg Asp Ala Gly Asn Cys val Ala Asp Gly Ile Cys Cys Asp $\rightarrow$ intron 2

גCF21 TCA G GTTGGAAGCTTTTACGCTCTTCAAATCAGGGGGGGGGAGGAGGGGAGATTTAAAGTTGCAACATGATTTATTTATTTTTTATTTATTTATTTTTTTTAT . (0.5 KD). .TGTATGTTAAACTAÄTG גCP31 - Ser G $\lambda C P 21$
$\lambda C 231$ $\rightarrow$ exon III

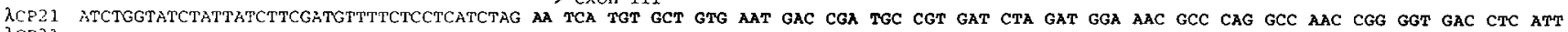
$\lambda C P 31$ lu Ser Cys Ala Val Asn Aso Arg Cys Arg Agp Leu Asp Gly Asn Ala Gln Ala Asn Arg Gly Asp Leu Ile ACF21 CAG TTG ATA CAC AAA CTC CTG AAA GTG AGG GAT TAC GAC TAA CCGGAAGTCAACTAAGCCGCCAAGCTCTGCTTCTCAGCCATGCGCGTCAGTGGTGGAAAACATGGCGGGAAGTGGTCCT $\lambda C P 31$ Gln Leu Ile his Lys Leu Leu Lys val arg Asp Tyx Asp gtop

$\lambda$ CE21 CAAGTCTCGCTTCTTPTGCATTTAGATAACGTGGGAAGTTGGTGTCTCAAACAAATGATTGTCTCAAACAGTTGCTTGTCACAAACAGATGATTGTCTCAAACAGTTGATTGCCACAAACAGCTGTTTGTCT ACP31 - -

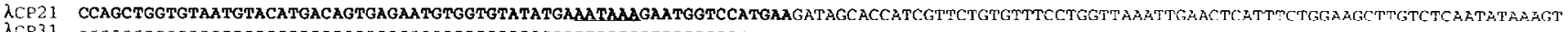

Figure 2. Organization and nucleotide sequence of the Lymnaea conopressin gene. $A$, Restriction maps of genomic clones $\lambda C P 56, \lambda C P 21$, and $\lambda C$ P 3I. Black boxes indicate the positions of exons I, II, and III. Recognition sites for the restriction endonucleases $B g l$ II $(B)$, Eco RI $(E)$, Hind III $(H), P s t$ I $(P)$, Sal I $(S)$, and $X b a$ I $(X)$ are indicated. Before exon II, the restriction maps of clones $\lambda C P 21$ and $\lambda C P 31$ differ due to polymorphism (see Discussion). The size bar represents $1 \mathrm{~kb}$. B, Nucleotide sequence of the conopressin gene. Relevant parts of clones $\lambda$ CP56, $\lambda$ CP21, and $\lambda$ CP31 were sequenced. Exon sequences are shown in bold face, as well as the predicted amino acid sequence of the conopressin precursor. Arrows indicate the beginning of exon I, II, and III, intron 1 and 2, the signal peptide domain, the conopressin domain, and the neurophysin domain. The transcription initiation site (the beginning of exon I) was determined by size determination of reverse transcription products of the conopressin mRNA (data not shown). The polyadenylation signal is underlined. Parts of the introns that were not sequenced are represented by dots. Of clone $\lambda C P 31$, only the nucleotides that differ from clone $\lambda \mathrm{CP} 21$ are shown, whereas the rest of the sequence is represented by dashes.

suggesting that Lys-conopressin and $\left[\right.$ Ile $\left.^{8}\right]$-conopressin interact with the same receptor.

\section{Membrane potential effects of conopressin on $C D C$}

Electrical stimulation of CDC in situ in the isolated CNS evoked an afterdischarge that lasted $\sim 50 \mathrm{~min}$. Bath application of conopressin resulted in a hyperpolarization of the membrane potential and an inhibition of electrical activity (Fig. 6). Due to the hyperpolarization, an increase in the spike amplitude occurred. To quantify the effect of conopressin, action potential frequencies were measured during $40 \mathrm{sec}$ before and $40 \mathrm{sec}$ after application of the peptide. Before application, a frequency of $0.7 \pm 0.2$ spikes/sec was observed, whereas afterwards the frequency was $0.4 \pm 0.1$ spikes/sec (mean $\pm \mathrm{SD} ; n=4$ ). Thus, conopressin significantly reduced the action potential frequency of the discharge $(p<0.02)$, whereas in control discharges, no reduction of action potential frequency was observed over the same time period (see also Kits, 1980).

\section{Discussion}

A single copy conopressin gene is the only member of the vasopressin/oxytocin gene family present in Lymnaea

We used several independent methods to examine the presence of vasopressin- and oxytocin-related peptides and corresponding genes in Lymnaea: peptide purification and characterization, PCR-amplification, and low-stringency hybridization of cDN $\Lambda$ and genomic DNA. Two antisera (W1E and 121) that specifically recognize the Pro-Lys/Arg-Gly-amide carboxy-terminal sequence typical of vasopressin and vasopressin-related peptides (Swaab and Pool, 1975; Liu and Burbach, 1987) were employed to detect vasopressin-related peptides in extracts of the brain. One of the two immunoreactive peptides that were identified 
Figure 3. Genomic Southern blot analysis of the Lymnaea conopressin gene. A blot containing Lymnaea genomic DNA digested with $B g l \mathrm{II}, E c o$ RI, Hind III, Pst I, and Xba I was hybridized at $55^{\circ} \mathrm{C}$ with a probe corresponding to the entire coding region of the conopressin cDNA, and washed at low stringency $(1 \times \mathrm{SSC} / 0.1 \%$ SDS, $55^{\circ} \mathrm{C}$; left panel $)$ and thereafter at high stringency $(0.2 \times \quad \mathrm{SSC} / 0.1 \% \quad \mathrm{SDS}$, $65^{\circ} \mathrm{C}$; right panel). No differences were observed between the hybridization patterns at these two washing conditions, except for some faint bands in the $B g l$ II and the Pst I lanes, which disappeared after high-stringency washing. Size markers are indicated between the two panels.

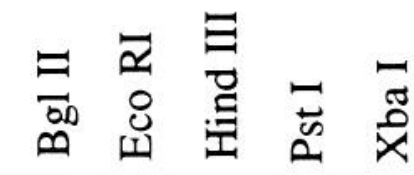

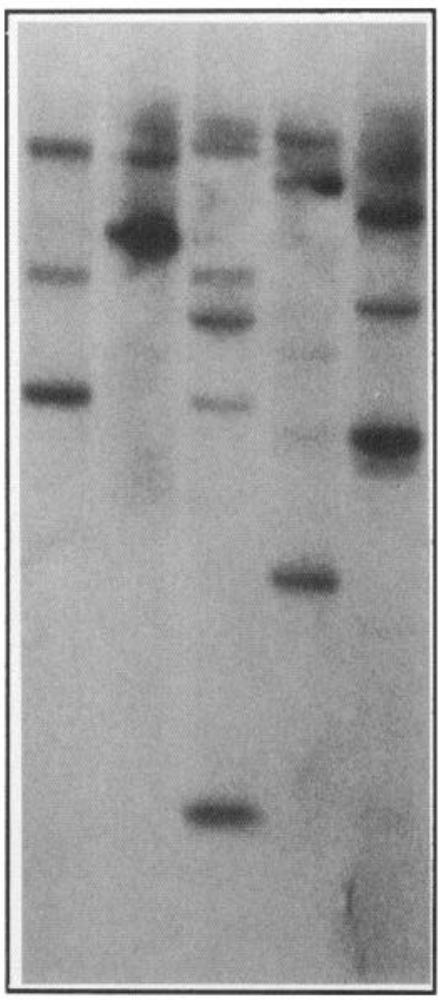

$1 x$ SSC; $0.1 \%$ SDS
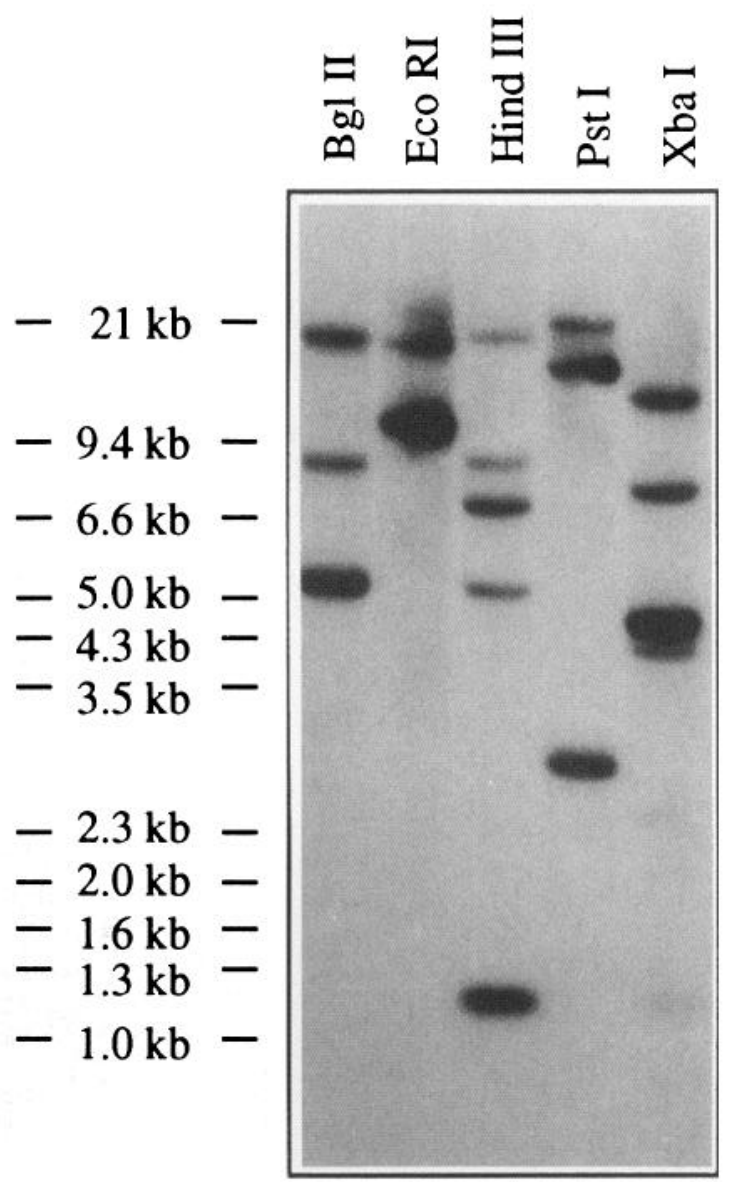

$0.2 \times$ SSC; $0.1 \%$ SDS from the brain has a primary structure identical to that of Lysconopressin, originally identified in C. geographus (Cruz et al., 1987), except that the cysteine residues at positions 1 and 6 and the carboxy-terminal amide could not be determined directly. However, because the $\mathrm{MH}^{+}$of the native peptide $(1036.7 \mathrm{Da})$ corresponds with the expected $\mathrm{MH}^{+}$of Lys-conopressin (1034.3 $\mathrm{Da}$ and as it co-elutes with synthetic Lys-conopressin in two rpHPLC systems, it must have a disulphide bridge involving cysteine residues at positions 1 and 6 , as well as an amidated carboxy-terminal glycine residue. Thus, Lymnaea conopressin is identical with Lys-conopressin and has the structural characteristics typical for vasopressin and related peptides, including the basic amino acid residue at position 8 .

To investigate the presence of oxytocin or oxytocin-related peptides in the Lymnaea CNS, we used a radioimmunoassay employing an antiserum that was raised against oxytocin. In displacement studies, this antiserum recognized the oxytocin-related peptides isotocin, mesotocin, and cephalotocin, but not vasopressin or vasotocin (G. Reich, personal communication). No immunoreactive peptides were found in HPGPC fractions of the Lymnaea CNS. However, the antiserum may not recognize all oxytocin-related peptides, and the absence of a peptide related to oxytocin in Lymnaea cannot be concluded on these grounds alone. Therefore, we examined the possibility that multiple members of the vasopressin/oxytocin gene family exist in Lym- naea. In mammals, the vasopressin and oxytocin genes consist of three exons, with a remarkably high-sequence identity between the second exon of each gene that is maintained by the mechanism of gene conversion (Ruppert et al., 1984). Consequently, vasopressin and oxytocin genes cross-hybridize, even under high stringency conditions (see for instance, Land et al., 1983). Members of multigene families are commonly identified by low-stringency hybridization using one of the genes as a probe (see for instance, Haeflinger et al., 1992; Carcia et al., 1995). Therefore, we applied low-stringency hybridization with conopressin cDNA to identify putative oxytocin-like cDNAs and genes in Lymnaea. In our experiments, hybridization conditions were chosen such that even sequences with only $50 \%$ sequence identity would have been detected (see Maniatis et al., 1982). A further lowering of the stringency resulted in a strong increase of background hybridization on genomic Southern blots, whereas no additional bands appeared (data not shown). We first screened a cDNA library of Lymnaea CNS under low-stringency conditions in order to find conopressin-related cDNAs. In addition to two conopressin clones, 24 positive clones were isolated; however, none of these clones encoded a conopressinrelated peptide precursor. Moreover, amplification of putative oxytocin-like sequences from the same cDNA library using a PCR approach that was previously used to isolate the conopressin cDNA did not result in the isolation of oxytocin-like cDNAs. 

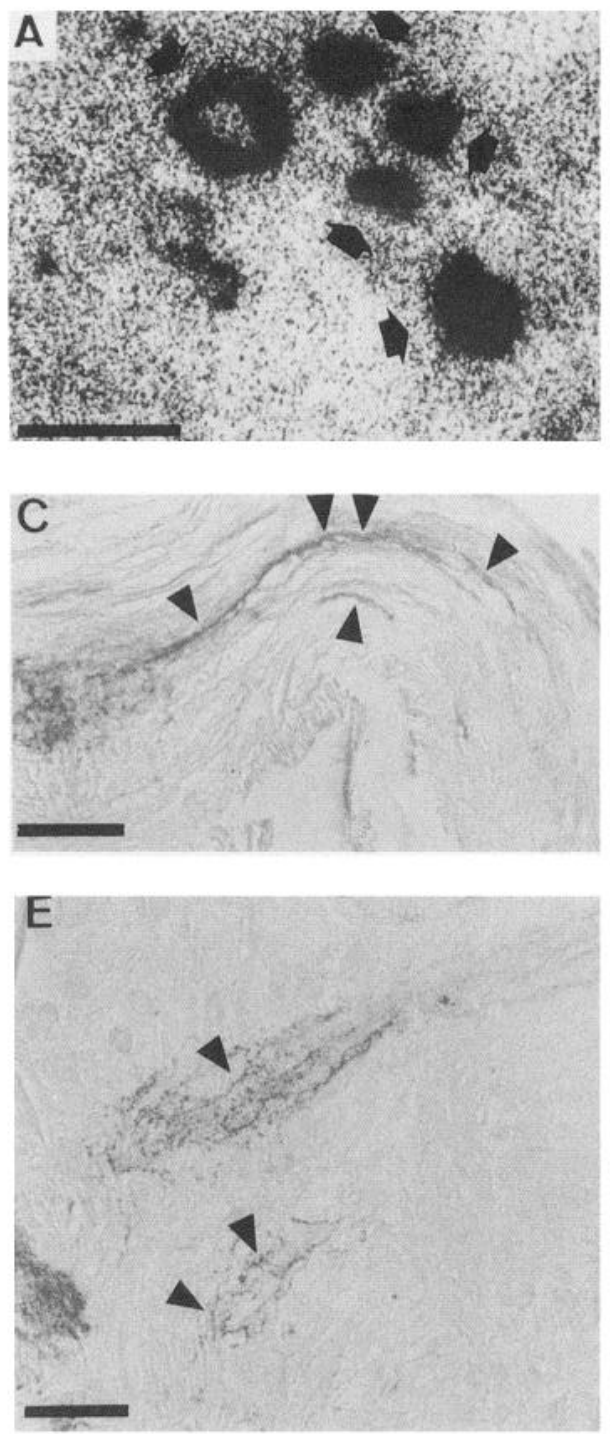
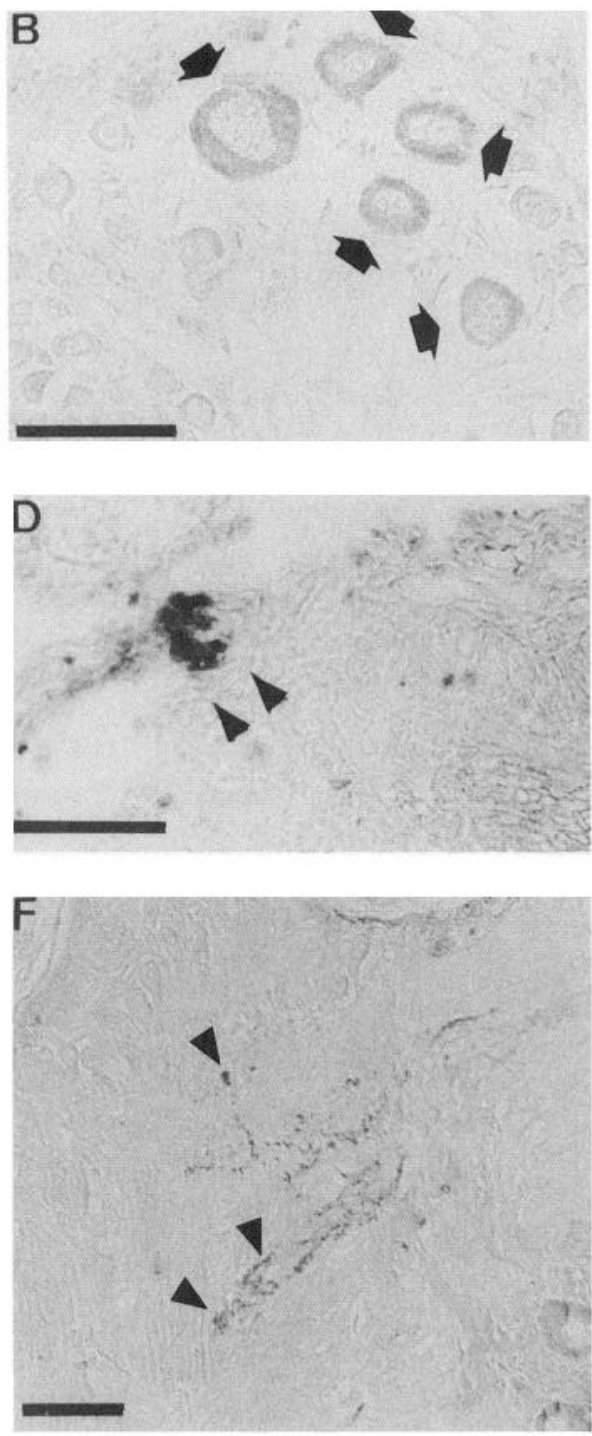

Figure 4. Localization of conopressin gene expression in anterior lobe neurons and of anti-neurophysin immunoreactivity in the CNS, the penis nerve, and the vas deferens. A, In situ hybridization of a section through the anterior lobe of the right cerebral ganglion with a proconopressin specific oligonucleotide probe. Arrows indicate anterior lobe neurons that express the conopressin gene. In the alternate section $(B)$, the same neurons are positively stained with the anti-neurophysin antiserum (arrows). C, Section through the origin of the penis nerve. Arrowheads indicate anti-neurophysin-positive axon bundles in the penis nerve. $D$, Crosssection through the vas deferens. Arrowheads indicate anti-neurophysinpositive axon bundles in the outer layer of the vas deferens. $E$, Section through the right cerebral ganglion. Arrowheads indicate anti-neurophysin-positive axons in the neuropile of the ganglion. These axons occur in the same location as anti-CDCH positive axons, as visualized in the alternate section (arrowheads in F), suggesting conopressinergic innervation of the CDC system. Some of the CDC somata are visible at the bottom right-hand corner in Figure F (Scale bars: $50 \mu \mathrm{m}$.)
Because both the screening and the PCR approach are restricted to genes that are expressed in the CNS, we also performed a screening of a genomic DNA library under low-stringency conditions. This resulted in the isolation of 17 clones that hybridized to the conopressin cDNA. All clones contain parts of the conopressin gene, as was verified by hybridization under high-stringency conditions to oligonucleotides specific for the leader sequence and the neurophysin domain of the conopressin cDNA, and by sequencing of the part encoding conopressin of all 10 clones that contain exon I. Together, these data show that an oxytocin-related peptide or gene can not be identified in Lymnaea using various well-established peptide chemical and molecular biological methods, and strongly suggest that conopres$\sin$ is the only member of the vasopressin/oxytocin superfamily in Lymnaea.

Restriction enzyme mapping and nucleotide sequencing revealed that the conopressin gene is split by two introns at exactly the same position as in the vasopressin and oxytocin genes (Fig. 2 ). Thus, the exon-intron organization of the members of vasopressin/oxytocin gene family has been conserved during at least 600 million years of evolution. Differences in the restriction maps and nucleotide sequences of clones $\lambda$ CP21 and $\lambda$ CP31 (Fig. 2) are very likely due to polymorphism, as the two clones do not encode different peptide precursors and the differences are almost exclusively restricted to the noncoding parts of the gene. To verify this, we performed genomic Southern blot hybridizations (Fig. 3). The conopressin cDNA probe identified multiple bands in each restriction enzyme digestion of genomic DNA when hybridized under low-stringency conditions $(1 \times$ SSC at $\left.55^{\circ} \mathrm{C}\right)$. After washing the blot at high stringency $(0.2 \times$ SSC at $65^{\circ} \mathrm{C}$ ), all bands remained equally intens, except for some faint bands in the $B g l$ II and the Pst I lanes, which disappeared. Since this was not observed in any of the other digestions, these bands are most likely due to aspecific hybridization under low stringency conditions. The Xba I lane (Fig. 3) showed that the two fragments $(1.2 \mathrm{~kb}$ and $4.5 \mathrm{~kb})$ containing exon II in clones $\lambda \mathrm{CP} 21$ and $\lambda \mathrm{CP} 31$ hybridized with different intensities, suggesting that they have an unequal distribution in the snail population and represent polymorphisms. Hybridization of the blot with exon-specific probes (not shown) revealed similar restriction site polymorphisms for the other enzymes used, except for $B g l$ II. In conclusion, these data show that all hybridizing fragments are derived from the conopressin gene, and that there is no evidence for an additional oxytocin-related gene in the Lymnaea genome. 


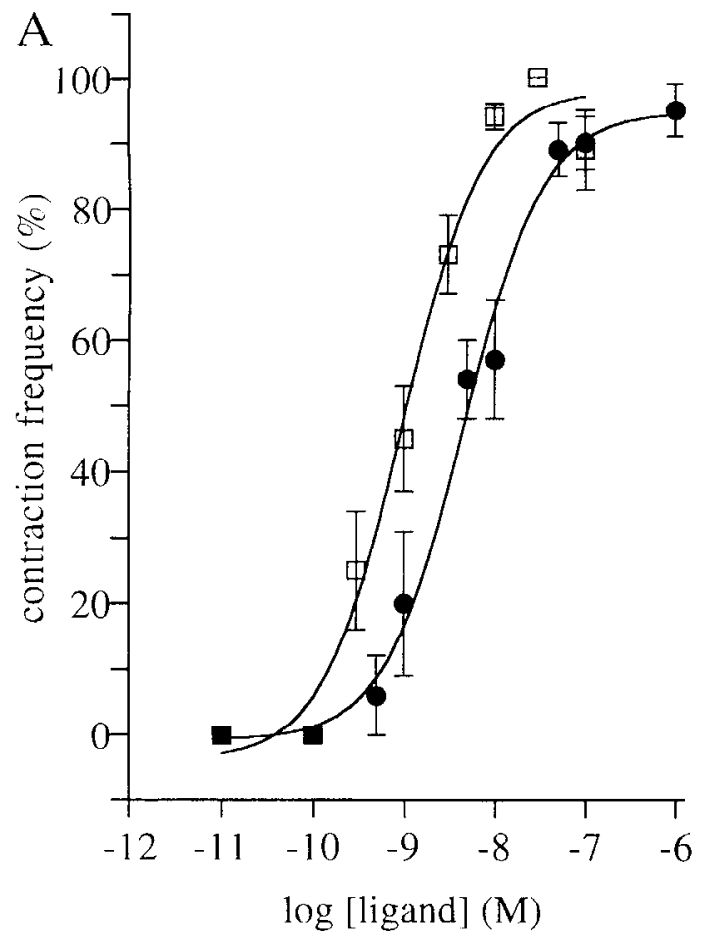

B

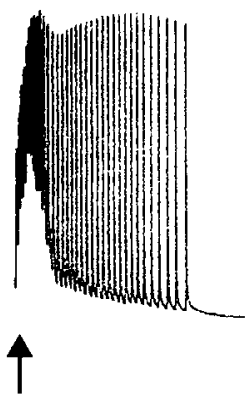

Lys-conopressin

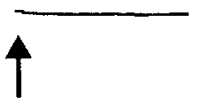

Lys-conopressin

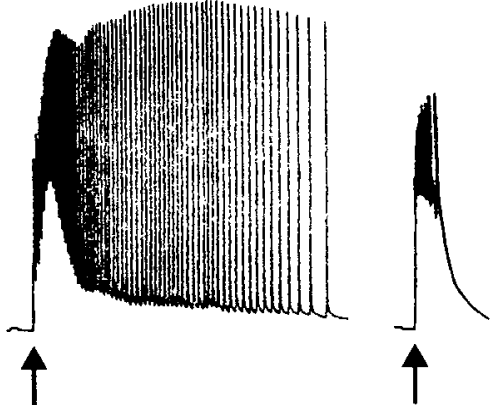

$\left[\right.$ Ile $\left.^{8}\right]$-conopressin

GLTPNMNSLFF-amide
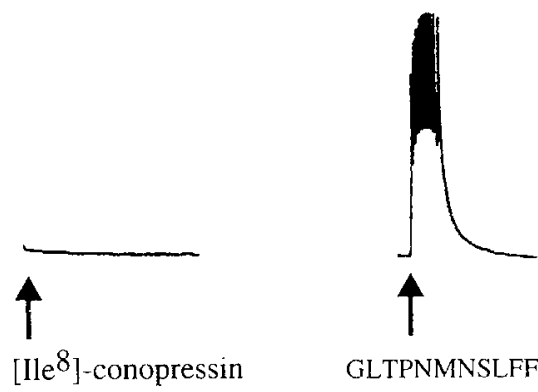

GLTPNMNSLFF-amide

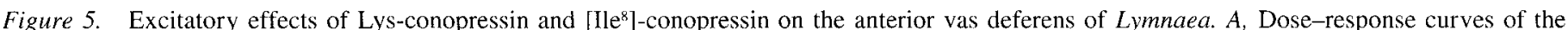
effects of Lys-conopressin (black circles) and [Ile $]$-conopressin (open squares) on the contraction frequency. The contraction frequency during the first minute after application of the peptide is expressed relative to the maximum frequency, and plotted semilogarithmically versus the peptide concentration. Means and SFM (error bars) are shown of three independent experiments. $B$, Responses to Lys-conopressin (3X $\left.10^{-8} \mathrm{M}\right)$, [Ile $\left.{ }^{8}\right]$ conopressin $\left(3 \times 10^{-8} \mathrm{M}\right)$, and the -FF-amide peptide (GLTPNMNSLFF-amide; $10^{-5} \mathrm{M}$ ) before (upper panel) and after (lower panel) desensitization of the conopressin receptor by repeated applications of Lys-conopressin. The response to the unrelated peptide does not desensitize.

\section{Conopressin is involved in the control of reproductive behavior}

The conopressin gene is expressed in neurons in the anterior lobes of both cerebral ganglia (Fig. $4 A, B$ ). These neurons were previously shown to project into the penis nerve to innervate the penis complex and the vas deferens (Smit et al., 1992; A. Ter Maat, A. W. Pieneman, and Y.A. Van Duivenboden, unpublished data). In accordance, conopressin immunopositive axon bundles were observed in the penis nerve and in the vas deferens (Fig. 4C,D), suggesting a possible role for conopressin in the control of the activities of the male copulation structures. This was further supported by the isolation and structural identification of Lys-conopressin from the penis complex and the vas deferens together.

Conopressin potently induced muscle contractions in the vas deferens at nM concentrations. The frequency of these contractions was dose dependent within a physiological range of conopressin concentrations, with an $\mathrm{EC}_{50}$ of $4.3 \mathrm{nM}$ (Fig. 5A). Thus, conopressin may be involved in the control of ejaculation of semen during intromission in Lymnaea, which nicely corresponds to the proposed role of oxytocin in the regulation of vas deferens activity and ejaculation of semen in mammals (Todd and Lightman, 1986; Murphy et al., 1987). In addition to effects on peripheral tissue, conopressin also affects central neurons involved in the regulation of reproductive behavior. Effects of Lysvasopressin on identified molluscan neurons have been noticed before (Barker and Gainer, 1974). In the present study, we observed that anti-neurophysin-positive axons occur in close proximity of the axons of the CDC (Fig. $4 E, F$ ), suggesting conopressinergic innervation of the CDC system. The CDCs are neu- roendocrine cells that release egg-laying peptides and control egg mass production and associated female reproductive behavior (Geraerts et al., 1991). Conopressin hyperpolarizes the CDC membrane potential and terminates an electrically triggered CDC discharge (Fig. 6), suggesting that conopressin may be able to inhibit peptide release by the CDC system and can prevent egg laying. These actions are meaningful in the context of the simultaneous hermaphroditic mode of reproduction of the animal, which necessitates a temporal patterning of the otherwise conflicting mating and egg-laying behaviors.

The vasopressin and oxytocin gene family: evolution of genes and functions

Our results support the view that an oxytocin-like peptide or gene is absent in Lymnaea. First, using immunological methods and well-characterized antisera, only the vasopressin-related peptide Lys-conopressin, but no oxytocin-related peptide could be identified in the CNS. Second, no conopressin-related cDNAs or genes could be identified using low-stringent hybridization as well as PCR amplification of oxytocin-like sequences. Third, the function of conopressin, i.e., control of reproductive behavior, is similar to that of oxytocin in mammals, suggesting that conopressin might represent an ancestral peptide of the vasopressin/ oxytocin superfamily, endowed with structural characteristics of vasopressin and functional characteristics of oxytocin. Therefore, we hypothesize that according to the current model the gene duplication that led to a vasopressin/oxytocin two-gene family occurred early during vertebrate evolution, and that in invertebrates, only one gene is present.

Thus, the presence in invertebrates of both vasopressin- and 


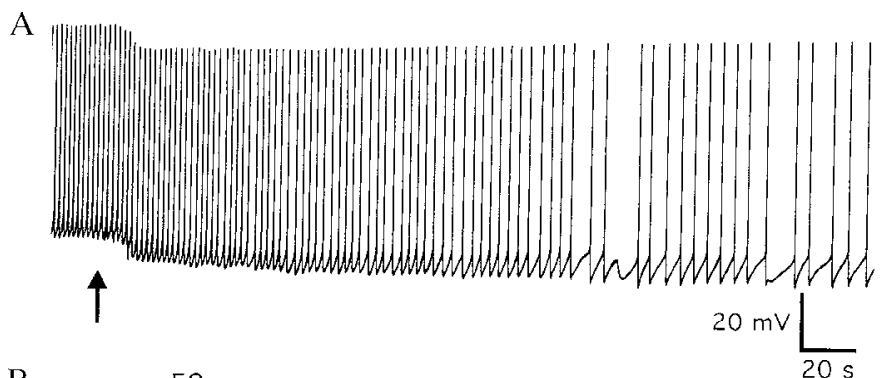

B

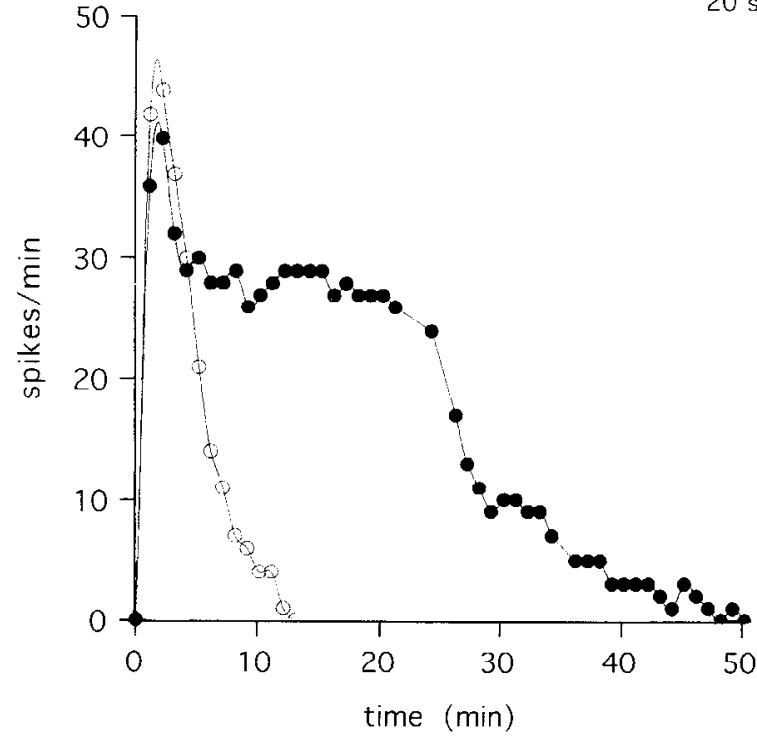

Figure 6. Membrane potential effects of conopressin on CDC. A, Membrane potential recording of a CDC in situ in the isolated CNS. An afterdischarge was evoked by electrical stimulation of the CDC and Lys-conopressin $\left(10^{-6} \mathrm{M}\right)$ was applied at $2.5 \mathrm{~min}$ after the onset of the discharge (arrow). Conopressin rapidly hyperpolarized the CDC membrane potential and reduced the firing frequency. As a result of the hyperpolarization, the spike amplitude increased. The spiking activity from $20 \mathrm{sec}$ before until $\sim 5 \mathrm{~min}$ after application of conopressin is shown. $B$, Hrequency plots of a control CDC dicharge (black dots) and a CDC discharge in the presence of conopressin (open dots). The control discharges lasted for $48 \mathrm{~min}$, whereas the discharges in the presence of conopressin lasted for 13 min (single representative of four independent experiments).

oxytocin-like peptides (i.e., peptides with a basic and peptides with an aliphatic amino acid residue at position 8 , respectively) results from the occasional mutation of a single gene rather than from gene duplication, and the mutation of residuc 8 from a basic to an aliphatic residue may therefore be neutral with respect to peptide-receptor interactions and peptide functions in invertebrates. To test this, we synthesized [ $\mathrm{Ile}^{8}$ ]-conopressin (i.e., Lys-conopressin with an isoleucine residue instead of a lysine residue at position 8 ), and compared its myoactive effect with that of Lys-conopressin. Isoleucine was substituted because oxytocin-related cephalotocin from Octopus, which is the closest related species to Lymnaea in which such a peptide has been identified, contains isoleucine at position 8 . Both peptides have similar potencies on the Lymnaea vas deferens (Fig. 5A) and interact with the same receptor, since desensitization of the receptor by Lys-conopressin resulted in a desensitized response to $\left[\mathrm{Ile}^{8}\right]$-conopressin, but not to an unrelated -FF-amide peptide that also acts as an excitatory transmitter on the vas deferens ( $\mathrm{Li}$ et al., 1995; Fig. 5B). Thus, the amino acid change that distinguishes vasopressin from oxytocin in mammals, is functionally neutral in Lymnaea. This may explain why mutation of residue 8 from a basic to an aliphatic residue occurred independently in the evolution of the various invertebrate phyla, without altering the functional properties of the peptide. In vertebrates, on the other hand, duplication of the gene followed by mutation of residue 8 in one of the genes, resulted in separate evolutionary lineages in which different receptors co-evolved with each peptide, yielding functionally distinct peptide-receptor combinations.

\section{References}

Acher R (1980) Molecular evolution of biologically active polypeptides. Proc R Soc Lond [Biol] 210:21-43.

$\Lambda$ cher R (1993) Neurohypophysial peptide systems: processing machinery, hydroosmotic regulation, adaptation and evolution. Regul Pept 45:1-13.

Barker JL, Gainer H (1974) Peptide regulation of bursting pacemaker activity in a molluscan neurosecretory cell. Science 184:1371-1372.

Barraud EM (1957) The copulatory behaviour of the freshwater snail (Lymnaea stagnalis L.). Br J Anim Behav 5:55-59.

Bogerd J, Van Kesteren RE, Van Heerikhuizen H, Geraerts WPM, Veenstra J, Smit AB, Joosse J (1993) Altenative splicing generates diversity of VD1/RPD2 alpha peptides in the central nervous system of Lymnaea stagnalis. Cell Mol Neurobiol 13:123-136.

Carcia CK, Brown MS, Pathak RK, Goldstein JL (1995) cDNA cloning of MCT2, a second monocarboxylate transporter expressed in different cells than MCT1. J Biol Chem 270:1843-1849.

Cruz LJ, De Santos V, Zafaralla GC, Ramilo CA, Zeikus R, Gray WR, Olivera BM (1987) Invertebrate vasopressin/oxytocin homologs: characterization of peptides from Conus geographus and Conus striatus venoms. J Biol Chem 262:15821-15824.

De Lange RPJ, Van Minnen J, Boer HH (1994) Expression and translation of the egg-laying neuropeptide hormone genes during postembrionic development of the pond snail Lymnaea stagnalis. Cell Tissue Res 275:369-375

Geraerts WPM, De With ND, Vreugdenhil E, Van Hartingsveldt W, Hogenes TM (1984) Studies on the physiological role of a partially purified small cardioactive neuropeptide of Lymnaea stagnalis. J Comp Physiol [B] 154:29-34.

Geraerts WPM, Smit AB, Li KW, Vreugdenhil E, Van Heerikhuizen H (1991) Neuropeptide gene families that control reproductive behaviour and growth in molluscs. In: Current aspects of the neurosciences (Osborne NN, ed), pp 255-304. London: MacMillan.

Haeflinger JA, Bruzzone R, Jenkins NA, Gilbert DJ, Copeland NG, Paul DL (1992) Four novel members of the connexins family of gap junction proteins: molecular cloning expression and chromosomal mapping. J Biol Chem 267:2057-2064.

Hara Y, Battey J, Gainer H (1990) Structure of mouse vasopressin and oxytocin genes. Mol Brain Res 8:319-324.

Heierhorst J, Lederis K, Richter D (1992) Presence of a member of the $T_{c} I$-like transposon family from nematodes and Drosophila within the vasotocin gene of a primitive vertebrate, the pacific hagfish Eptatretus stouti. Proc Natl Acad Sci USA 89:6798-6802.

Ivell R, Richter D (1984) Structure and comparison of the oxytocin and vasopressin genes from rat. Proc Natl Acad Sci USA 81:20062010.

Kits KS (1980) States of excitability in ovulation hormone producing neuroendocrine cells of Lymnaea stagnalis (Gastropoda) and their relation to the egg-laying cycle. J Neurobiol 1 1:397-410.

Kits KS, Crest M, Bobeldijk RC, Lodder JC (1991) Glucose-induced excitation in molluscan central neurons producing insulin-related peptides. Pflugers Arch 417:597-604.

Land H, Grez M, Ruppert S, Schmale H, Rehbein M, Richter D, Schütz $G$ (1983) Deduced amino acid sequence from the bovine oxytocinneurophysin I precursor cDNA. Nature 302:342-344.

Lane TF, Sower SA, Kawauchi H (1988) Arginine vasotocin from the pituitary gland of the lamprey (Petromyzon marinus): isolation and amino acid sequence. Gen Comp Endocrinol 70:152-157.

Lasham A, Darlison MG (1993) Direct sequencing of lambda-DNA from crude lysates using an improved linear amplification technique. Mol Cell Probes 7:67-73.

Li KW, Geraerts WPM, Van Elk R, Joosse J (1989) Dot immunobinding assay of high performance liquid chromatographic fractions on poly(vinylidene difluoride) membrane. J Chromatogr 472:445-446. 
Li KW, Smit AB, Geraerts WPM (1992) Structural and functional characterization of neuropeptides involved in the control of male mating behavior of Lymnaea stagnalis. Peptides 13:633-638.

Li KW, El Filali Z, Van Golen FA, Geraerts WPM (1995) Identification of a novel amide peptide, GLTPNMNSLFF-NH $\mathrm{N}_{2}$, involved in the control of vas deferens motility in Lymnaea stagnalis. Eur $\mathbf{J}$ Biochem 229:70-72.

Liu B, Burbach JPH (1987) Characterization of vasopressin and oxytocin immunoreactivity in the sheep and rat pineal gland: absence of vasotocin and detection of a vasopressin-like peptide. Peptides 8:711.

Maniatis T, Fritsch EG, Sambrook J (1982) Molecular cloning: a laboratory manual. Cold Spring Harbor, NY: Cold Spring Harbor Laboratory.

McMaster D, Kobayashi Y, Lederis K (1992) A vasotocin-like peptide in Aplysia kurodai ganglia: HPLC and RIA evidence for its identity with Lys-conopressin G. Peptides 13:413-421.

Morlcy SD, Schönrock C, Hcicrhorst J, Figucroa J, Lcderis K, Richter D (1990) Vasotocin genes of the teleost fish Catastomus commersoni: gene structure, exon-intron boundary, and hormone precursor organization. Biochemistry 29:2506-2511.

Murphy MR, Seckl JR, Burton S, Checkley SA, Lightman SL (1987) Changes in oxytocin and vasopressin secretion during sexual activity in men. J Clin Endocrinol Metab 65:738-741.

Oumi T, Ukena K, Matsushima O, Ikeda T, Fujita T, Minakata H, Nomoto K (1994) Annetocin: an oxytocin-related peptide isolated from the earthworm, Eisenia foetida. Biochem Biophys Res Commun 198: 393-399.

Proux JP, Miller C $\Lambda$, Li JP, Carney PL, Girardie $\Lambda$, Delaage M, School ey DA (1987) Identification of an arginine vasopressin-like diuretic hormone from Locusta migratoria. Biochem Biophys Res Commun 149:180-186.

Ramsay DJ (1983) Posterior pituitary gland. In: Basic and clinical endocrinology (Greenspan FS, ed), pp 177-187. Englewood Cliffs, NJ: Prentice-Hall.

Reich $G$ (1992) A new peptide of the oxytocin/vasopressin family isolated from nerves of the cephalopod Octopus vulgaris. Neurosci Lett 134:191-194.

Ruppert S, Scherer G, Schütz G (1984) Recent gene conversion in- volving bovine vasopressin and oxytocin precursor genes suggested by nucleotide sequence. Nature 308:554-557.

Salzet M, Bulet P, Van Dorsselaer A, Malecha J (1993) Isolation, structural characterization and biological function of a lysine-conopressin in the central nervous system of the Pharyngobdellid leech Erpobdella octoculata. J Biochem 217:897-903.

Sanger F, Nicklen S, Coulson AR (1977) DNA sequencing with chainterminating inhibitors. Proc Natl Acad Sci USA 74:5463-5467.

Sausville E, Carney D, Battey J (1985) The human vasopressin gene is linked to the oxytocin gene and is selectively expressed in a cultured lung cancer cell line. J Biol Chem 260:10236-10241.

Schmale H, Heinsohn S, Richter D (1983) Structural organization of the rat gene for the arginine vasopressin-neurophysin precursor. EMBO J 2:763-767.

Smit AB, Jiménez CR, Dirks RW, Croll RP, Geraerts WPM (1992) Characterization of a cDNA clone encoding multiple copies of the neuropeptide APGWamide in the mollusc Lymnaea stagnalis. J Neurosci 12:1709-1715.

Swaab DF, Pool CW (1975) Specificity of oxytocin and vasopressin immunofluorescence. J Endocrinol 66:263-272.

Todd K, Lightman SL (1986) Oxytocin release during coitus in male and female rabbits: effect of opiate receptor blockade with nalaxone. Psychoneuroendocrinology 11:367-371.

Van Kesteren RE, Smit $\Lambda B$, Dirks RW, De With ND, Geraerts WPM, Joosse J (1992) Evolution of the vasopressin/oxytocin superfamily: characterization of a cDNA encoding a vasopressin-related precursor, preproconopressin, from the mollusc, Lyrrnata stagralis. Proc Natl Acad Sci USA 89:4593-4597.

Van Minnen J, Schallig H (1990) Demonstration of insulin-related substances in the central nervous system of pulmonates and Aplysia californica. Cell Tissue Res 260:381-386.

Van Minnen J, Dirks RW, Vreugdenhil E, Van Diepen J (1989) Expression of the egg-laying hormone genes in peripheral neurons and endocrine cells in the reproductive tract of the mollusc Lymnaea stagnalis. Neuroscience 33:35-46.

Vreugdenhil E, Jackson JF, Bouwmeester T, Smit AB, Van Minnen J, Van Heerikhuizen H, Klootwijk J, Joosse J (1988) Isolation, characterization and evolutionary aspects of a cDNA clone encoding multiple neuropeptides involved in the stereotyped egg-laying behavior of the freshwater snail Lymnaea stagnalis. J Neurosci 8:4184-4191. 